\title{
Stage IIB Primary Peritoneal Cancer AJCC v8
}

National Cancer Institute

\section{Source}

National Cancer Institute. Stage IIB Primary Peritoneal Cancer A/CC v8. NCI Thesaurus.

Code C140007.

Stage IIB includes: T2b, NO, M0. T2b: Primary peritoneal cancer with tumor extension to and/or implants on other pelvic tissues. N0: No regional lymph node metastasis. M0: No distant metastasis. (AJCC 8th Ed.) 